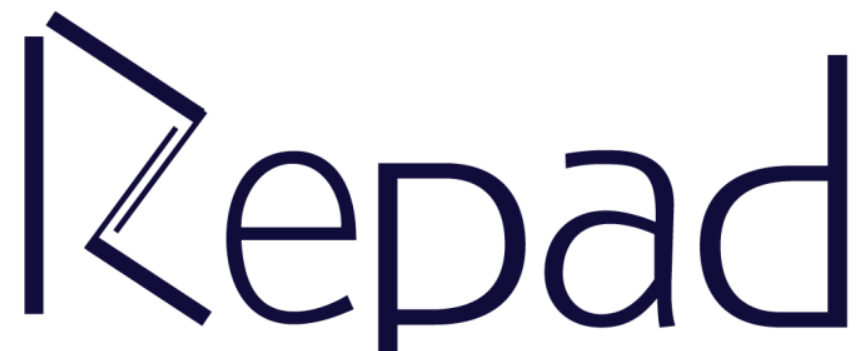

Vol. 1, N. 1 Dezembro/2017

Revista Estudos e

Pesquisas em Administração

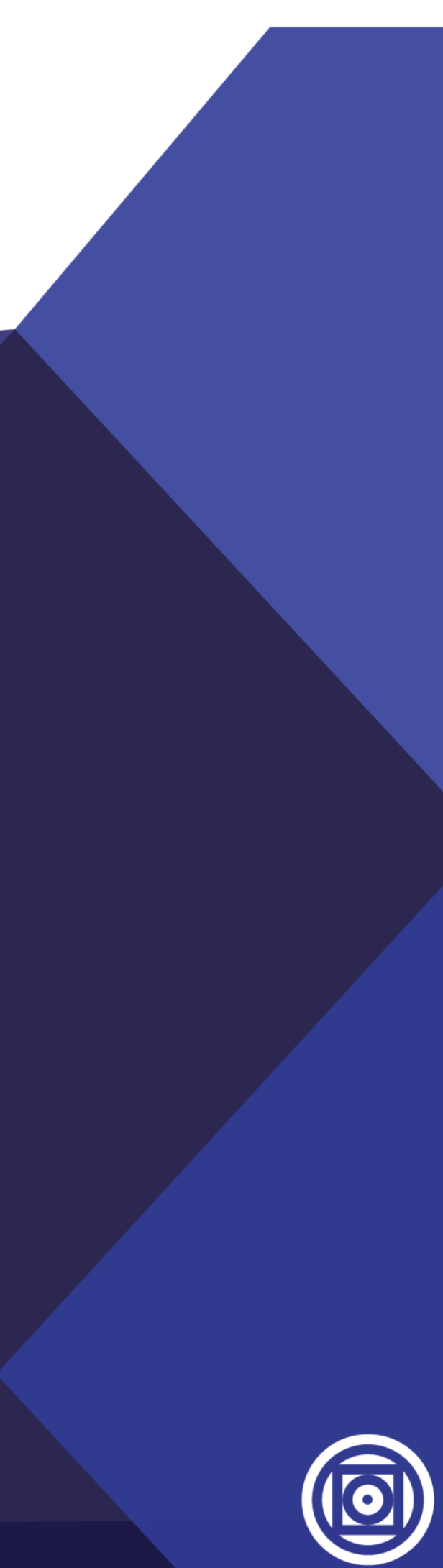




\title{
ANÁLISE DAS PERSPECTIVAS DE EMPRESAS EM RELAÇÃO À IMPLANTAÇÃO DE UM PARQUE FERROVIÁRIO NO DESENVOLVIMENTO PRODUTIVO LOCAL: Uma análise no distrito industrial de Rondonópolis-MT
}

Higor José dos Santos Bacharel em Administração e MBA em Finanças e Controladoria pela Universidade Federal de Mato Grosso

\section{RESUMO}

A cidade de Rondonópolis respira a dualidade do cenário urbano e rural sendo a mais industrializada e um dos polos agrícolas do estado de Mato Grosso, fatores que influenciaram a instalação de um parque ferroviário na cidade para o escoamento da produção agrícola. $\mathrm{O}$ contexto produtivo instiga questionamentos a respeito do uso do transporte ferroviário para além do escoamento da produção agrícola, sendo utilizado pelas empresas manufatureiras. $\mathrm{O}$ trabalho, então, objetivou analisar a perspectivas das empresas manufatureiras dos distritos industriais da cidade em relação ao uso do modal ferroviário. A pesquisa seguiu um formato teórico-empírico e descritiva, com abordagem qualitativa e uma orientação de categorização na análise dos dados evidenciados por meio de coleta documental, registros, entrevistas e observação direta em campo das percepções dos gestores. Os resultados apontam que o Brasil já tem intrínseco em sua cultura administrativa o uso do modal ferroviário para projetos estratégicos de locomoção, o que acarreta, dentre outros problemas, a perda de vantagem competitiva para as empresas envolvidas.

Palavras-chave: Logística; Clusters; Rondonópolis: Modal Ferroviário.

\section{ANALYSIS OF COMPANIES' PERSPECTIVES ABOUT THE IMPLEMENTATION OF A RAILROAD STATION IN THE LOCAL PRODUCTIVE DEVELOPMENT: An analysis in the industrial district of Rondonópolis-MT}

\begin{abstract}
The city of Rondonópolis presents the duality of the urban and rural environments, being the most industrialized city and one of the agricultural centers in the state of Mato Grosso, factors that influenced the installation of a railroad station the city, to distribute the agricultural production. The productive context instigates questions about the use of rail transport beyond the flow of the agricultural production, being used by manufacturing companies. Thus, the work aimed to analyze the perspectives of manufacturing companies in the industrial districts of the city regarding the use of the railways. The research followed a theoretical, empirical and descriptive format, with a qualitative approach and a categorization guidance in data analysis evidenced by documentary collection, records, interviews and direct field observation of managers' perceptions. The results show that the use of railways for strategic projects of movement is already intrinsic in Brazil's administrative culture, which entails, among other problems, the loss of competitive advantage for the companies involved.
\end{abstract}

Keywords: Logistics; Clusters; Rondonópolis: Rail transportation. 


\section{INTRODUÇÃO}

Os crescimentos dos setores de produção, independentemente de seu mercado de atuação, fomentam a necessidade de um transporte eficiente e, para alimentar esse desenvolvimento, a logística tem o papel de atender essa demanda com o intuito de satisfazer todas as partes envolvidas e agregar valor ao produto.

"A logística é uma função vital que deve ser executada por virtualmente qualquer tipo de firma ou instituição [...]." (BALLOU, 2012, p.335). Sendo assim e, conforme o raciocínio de Ballou (2012), a logística é uma ferramenta de vantagem competitiva para as empresas que visam um processo produtivo e eficiente, integrando seus diferentes setores, dando agilidade na movimentação de insumos e produtos, reduzindo seus custos e controlando seu fluxo de informação.

Para Almeida e Schlüter (2012, p.43) "[...] a sua finalidade é acrescentar valor ao produto ao torná-lo disponível, entretanto, a disponibilidade e entrega desse produto tem como meta, antes de mais nada, acrescentar valor ao cliente".

Isso leva a dizer que, conforme os autores, a logística está incumbida de enfrentar e solucionar os problemas relacionados a tempo e espaço, encontrando soluções econômicas ótimas para suprir as necessidades dos envolvidos.

Rodrigues (2014, p.158) relata quatro valores agregados ao produto ao longo da cadeia logística; forma, é agregado pela produção, está relacionado com o atendimento das especificações de qualidade e quantidade, espaço, valor agregado pelo transporte, atendendo o desejo do cliente em receber o produto em um lugar específico, tempo, este valor pode ser agregado por qualquer parte integrante da cadeia, com o suporte do transporte, consiste em cumprir a entrega no prazo de maneira efetiva, e posse, efetiva troca de titularidade do produto disponibilizado, esse valor depende da coordenação de diferentes ações, sendo identificado na distribuição física.

Dos quatro valores agregados ao produto citados por Rodrigues (2014) o transporte possui ligação efetiva com três (espaço, tempo e posse), o que enfatiza a importância do mesmo em uma cadeia produtiva. Importância essa que nos leva a refletir o quão importante seria o uso do modal ferroviário pelas empresas manufatureiras de Rondonópolis-MT.

O objetivo que norteou a pesquisa constituiu em analisar a perspectivas dos gestores de empresas manufatureiras, instaladas nos distritos industriais de Rondonópolis, quanto ao uso do modal ferroviário, tanto para aquisição de matéria-prima e para o escoamento de produção e como isso impacta em seus negócios.

Buscou-se relatar os incentivos dos órgãos públicos para o uso das empresas quanto ao modal ferroviário, identificar os motivos de escolha dos modais utilizados pelas empresas e identificar os aspectos positivos e negativos nas empresas com a inserção do parque ferroviário na cidade.

A metodologia seguiu um formato teórico-empírico e descritivo, com abordagem qualitativa, e uma orientação de categorização na análise dos dados evidenciados por meio de coleta documental, registros, entrevistas e observação direta em campo das percepções dos gestores.

\section{TRANSPORTE E O CANAL DE DISTRIBUIÇÃO}

O canal é o meio utilizado para a transferência de insumos, produtos e serviços entre os membros da cadeia, agregando valor aos produtos e serviços ofertados aos usuários finais utilizando-se da geração de valor relacionados a tempo, espaço e posse. 
Harrison e Van Hoek (2003) citado por Almeida e Schlüter (2012, p.70) apontam cinco aspectos capazes de ampliar a vantagem competitiva das empresas, relacionado à cadeia de suprimentos:

- Qualidade: o produto deve ser entregue ao cliente em condições perfeitas, levando o nível de insatisfação dos mesmos a um nível inexistente. Problemas com indisponibilidade, defeito e atraso são sintomas da falta de qualidade no atendimento, o que pode ocasionar dificuldade em fidelização.

- Velocidade: está relacionada ao tempo que o cliente está disposto a esperar para receber o produto, o tempo pode variar de imediato até anos de espera. O tempo é contado do dia do pedido até a data de entrega.

- Tempestividade: cumprimento de tudo o que foi combinado ou prometido, desde horários, local e condições do produto.

- Flexibilidade: ser flexível a novos produtos e mercados, a fim de atender novas demandas de mercado. A flexibilidade assume quatro formas, a do produto mede a rapidez de lançamento de novos produtos, a flexibilidade do mix que mede o tempo que leva para trocar entre diferentes produtos uma determinada variedade, a flexibilidade de volume que mede o tempo de resposta perante as variações da demanda, e a flexibilidade da entrega que mede a capacidade de modificar as entregas.

- Custos: baixos custos traduzem vantagem através de preços baixos ou margem alta de lucro.

Os sistemas de transporte têm como utilidade movimentar pessoas e cargas, independente do estágio de transformação em que os produtos se encontram. Para isso, o transporte faz uso dos recursos temporais, tempo e espaço, para concluir suas tarefas com a maior eficiência possível. Sendo assim, possui ligação direta com os supracitados ligados ao ganho de vantagem competitiva.

Bowersox et al. (2006) citado por Almeida e Schlüter (2012, p.102) afirma que há dois princípios que atuam sobre a eficiência dos transportes na logística, o primeiro é a economia de escala, que está relacionada à diminuição do custo por unidade de peso à medida que o volume de carga aumenta, e a economia de distância, que está relacionada à diminuição do custo de transporte por unidade de peso à medida que aumentam a distância percorrida.

O Brasil ser um país com amplas extensões territoriais, cada região possui características econômicas, físicas e sociais peculiares, o que influencia diretamente na escolha do modal a ser utilizado em determinada região.

Com isso, "o processo de escolha modal para o transporte de carga envolve diversos aspectos como características de mercado, dos tomadores de decisão e das cargas, legislação, infraestrutura de transportes e tecnologias disponíveis" (CAIXETA-FILHO; MARTINS, 2014, p.240).

Para auxílio da "ferramenta" logística, transporte, segundo Sales (2000, p.68) deve-se criar um roteiro para especificar os pontos de demanda que serão atendidas e o tempo em que serão atendidas, essa roteirização envolve a escolha das melhores rotas para cumprimento do trajeto de maneira eficiente.

O objetivo dessa roteirização, segundo o autor, é apoiar decisões referentes à criação, planejamento, verificação de rotas, planejamento de canais de distribuição e formação de cargas.

Caixeta-filho e Martins (2014) apontam algumas variáveis relevantes na escolha do modal de transporte: custo de operação, tempo de trânsito, frequência do serviço, serviços logísticos oferecidos adicionais ao transporte, disponibilidade e qualidade das informações de 
transporte, capacidade, confiabilidade, acessibilidade e flexibilidade de integração modal e segurança, perdas e danos.

O transporte rodoviário é realizado em estradas de rodagem com diversos tipos de veículos, abrangendo fronteiras; municipais, regionais, estaduais, nacionais e internacionais. Esse modal é o único capaz de realizar serviços até o cliente final de maneira independente, exige um alto consumo de combustível e é o mais indicado para transportes de alto valor. (RODRIGUES, 2014, p.53-56).

O Brasil apresenta uma grande malha rodoviária que em sua maioria, por conta das más administrações federais e estaduais, encontra-se em péssimas condições de uso. Esse sistema é composto por transportadores particulares, frotas e empresas logísticas e transporte, suas operações possuem custos fixos baixos e custos variáveis altos e possui um mercado muito competitivo no Brasil. (ALMEIDA; SCHÜTLER, 2012, p.110-111).

Conforme Gordinho (2003), em 1945 houve a aprovação da Lei Joppert que criara o Fundo Rodoviário Nacional, que garantiu investimentos para a implantação da grande rede rodoviária no país. Os anos subsequentes consolidaram as rodovias como modalidade de integração do território brasileiro.

Gordinho (2003) relata que, em 1952 estudos realizados entre Estados Unidos e Brasil indicaram a expansão da infraestrutura rodoviária era a mais econômica para o país, se comparada a outras. Na relação custo-benefício, as rodovias apresentam menores custos de implantação e mais rápido retorno de investimentos, dado o tamanho do território e a produção dispersa. Além disso, essa opção se beneficiou pelo Programa do Petróleo Nacional e pela criação da Petrobrás em 1951, que em 1954 passou a produzir o asfalto que fomentou a malha rodoviária.

É o modal mais expressivo no transporte de cargas do país atingindo praticamente todos os pontos do território nacional, se destinando principalmente a movimentação de distancias mais curtas. (RIBEIRO; FERREIRA, 2000, p. 02-03).

- Vantagens: mais vias de acesso que resultam na flexibilidade de serviço, atendimento de maneira individual, atendimento de regiões remotas, entregas rápidas e fácil substituição de equipamento em caso de danos (RODRIGUES, 2014, p.56).

- Desvantagens: não indicados a distâncias superiores a 500 km, capacidade de carga menor que de outros modais, alto nível de restrições de segurança, intensidade de tráfego, desgaste da malha rodoviária (RODRIGUES, 2014, p.57).

As ferrovias consistem em um sistema de transporte sobre trilhos, que compreende instalações fixas interligadas por vias, o equipamento de tráfego e o material rodante. Apesar de apresentar um custo fixo alto para a implantação, esse modal apresenta custos operacionais baratos e eficiência energética quando eletrificado por inteiro (RODRIGUES, 2014, p.65-68).

O modal ferroviário se apresenta como um transportador de longo curso e lento, e seu alto custo fixo são decorrentes do valor dos equipamentos, direito ao uso com a privatização, implantação de linhas, pátios de manobras e terminais. O modal é utilizado, principalmente, para transportar produtos extrativos localizados distantes dos portos e hidrovias (ALMEIDA; SCHÜTLER, 2012, p.104).

Segundo Ribeiro e Ferreira (2000. p.02) citado por Ballou (1993, p.127), há dois tipos de serviços ferroviários, o transportador regular, que presta serviço para qualquer usuário e é regulamentado pelo governo, e o transportador privado, sem propriedade particular, que o usa com exclusividade. 
No país, existem bitolas de tamanhos diferentes impossibilitando o estabelecimento de fluxos integrados interferroviários para o escoamento de cargas via ferroviária. A sucessão dos governos militares consolidou a malha em poucas empresas públicas e erradicaram os ramais ineficientes, planejando apenas projetos considerados estratégicos (RODRIGUES, 2014, p.66).

Conforme Almeida e Schütler (2012, p.105), "as ferrovias são seguras, apresentam baixo risco e não são gravemente prejudicadas pelo tempo ou tráfego competitivo".

- Vantagens: capacidade de transporte grandes lotes a longas distâncias, terminais privados no centro de produção, baixo frete, baixo consumo energético e provê estoque em trânsito (RODRIGUES, 2014, p.69).

- Desvantagens: baixa velocidade, custos elevados em relação a transbordo, baixa flexibilidade de rotas, alta exposição a furtos (RODRIGUES, 2014, p.69).

No Brasil, o transporte rodoviário corresponde a $66 \%$ da movimentação de cargas, o ferroviário corresponde a $21 \%$, e por cabotagem corresponde a $13 \%$, sendo que a intermodalidade é mais intensa na movimentação de produtos de baixo valor agregado (como; minério de ferro e grãos). A dependência do transporte rodoviário fica ainda mais nítida na movimentação dos produtos de alto valor agregado, correspondendo a 87\% (NOVAES et al., 2007, p. 3).

A intermodalidade significa utilizar mais de um modal numa mesma viagem, as empresas utilizam desse serviço para reduzir os custos sem reduzir o nível de serviço ofertado. Sendo assim, pode-se atingir os objetivos pretendidos minimizando os custos (ALMEIDA; SCHÜTLER, 2012, p.115).

Para Companhia Nacional de Abastecimento-CONAB (2005) citado por Silva (2010), a matriz do transporte brasileiro não condiz com a realidade de nossa extensão territorial, pelo qual deve-se priorizar os transportes ferroviários e hidroviários. Relação essa, evidenciada no escoamento de produtos agropecuários, que possuem baixo valor agregado e precisam ser escoados em grandes quantidades.

Outro aspecto a ser considerado pelo transporte ferroviário é a integração intra e intermodal, já que evidencia problemas com os diferentes tipos de bitola, transposição de áreas urbanas, direitos de passagem entre concessionárias, baixa oferta de terminais de integração intermodal, inviabilizam o uso do modal ferroviário em longas distâncias, quando o mesmo se torna mais competitivo. (NOVAES et al., 2007, p. 3)

\section{DISTRITOS INDUSTRIAIS}

Fragomeni (2005) citado por Hoenicke (2007, p.14) descreve os distritos como uma fração do território subdividida e alocada para uso de diversas empresas que compartilham a mesma infraestrutura e são projetados para atender a demandas compatíveis de diferentes indústrias. São concebidos com dimensão gerencial e responsáveis por provisionar serviços de suporte.

A origem desta zona deve-se a descentralização das grandes empresas, que passaram a contratar pequenas tarefas dessas empresas com o objetivo de reduzir deseconomias metropolitanas e contornar problemas resultantes dos salários e pouca mobilidade dos trabalhadores (AZEVEDO, 2003, p.100).

Diversos autores conceituaram o fenômeno de concentração de empresas e propuseram diferentes denominações, destacam-se: cluster (PORTER, 1990; 1999), sistemas industriais localizados (COURLET, 1993), distritos industriais (BAGNASCO, 2000; BRUSCO, 1982; 
SCHMITZ, 1995), aglomerados (DINIZ, 2000) e agrupamentos (CNI, 1998 apud TIRONI, 2001; MACHADO, 2003, p. 2).

No Brasil o termo mais utilizado é o de arranjo produtivo local (APL) que, segundo Machado (2003, p.2) citado por Banco Nacional do Desenvolvimento-BNDES (2003) "é uma concentração geográfica de empresas e instituições que se relacionam em um setor particular. Incluem, em geral, fornecedores especializados, universidades, associações de classe, instituições governamentais e outras organizações [...]".

Buarque (1984) citado por Lauria (2014, p. 22) afirma que, o que determina a localização dos distritos é a localização dos insumos, dos materiais de produção, disponibilidade da mão-de-obra, espaço físico disponível, clima, distância da fonte de combustível industrial, facilidade de transporte, distância e dimensão do mercado, disponibilidade de energia, água, luz e telefone, saneamento básico, segurança, incentivos e estrutura tributária.

Machado (2003, p.02-03) apresenta como vantagens dos arranjos produtivos locais a "proximidade à matéria-prima e infraestrutura de transportes [...] a proximidade ao mercado consumidor, a especificidade do produto, a presença de mão-de-obra e empresários qualificados, presença de fornecedores de equipamentos e outros insumos especializados [...]".

Os clusters designam um agrupamento de empresas em uma base geográfica, possuem como ponto de partida um determinado produto de consumo final e a partir dele as empresas iniciam a sua organização rumo à matéria-prima, beneficiando ou extraindo partes do produto de consumo final. (ALMEIDA; SCHÜTLER, 2012, p.278)

Azevedo (2003, p.102) relata a existência de três tipos, nos países em desenvolvimento: o primeiro são os formados por micro e pequenas empresas, voltadas para um mercado de baixa renda; o segundo são os de produção em massa, criados para a substituição de importações; e o terceiro são os formados com multinacionais, com baixa relação com as empresas locais e voltadas para mercado mundial.

Clusters são denominados por aglomeração industrial, mas comumente de pequeno e médio porte, apresentam elevado nível de entrosamento e afinidade. É constituído de firmas autônomas e articuladas, sendo estas apoiadas em outras instituições mantenedoras de suporte de recursos humanos, financeiros, tecnológicos, de infraestrutura e outros fatores que asseguram suas necessidades (SOUSA 2003).

No Brasil, distrito industrial é definido como área industrial planejada e exclusivamente vinculada a um perímetro urbano, e dotado necessariamente de infraestrutura física e serviços de apoio que fomentam o desenvolvimento industrial. (HOENICKE, 2007)

\section{PROCEDIMENTOS METODOLÓGICOS}

O município de Rondonópolis é cortado pelas rodovias federais BR364 e BR163, sendo as mais importantes vias de escoamento da produção do estado, além de ligarem as regiões Norte e Sul do estado. Importante localização geográfica, que tornou a cidade polo industrial do Centro-Oeste.

Atualmente, o município de Rondonópolis possui, no total, cinco distritos industriais localizados em seu perímetro urbano, que posteriormente serão apresentados, sendo três privados e dois públicos. Esses distritos abrigam a maioria das indústrias instaladas na cidade.

O distrito industrial Anézio Pereira de Oliveira, o micro distrito industrial da Vila Operária, conforme os dados fornecidos pela prefeitura Municipal de Rondonópolis, possui apenas uma empresa instalada em sua área. 
O distrito industrial de Rondonópolis, o primeiro distrito da cidade, conforme dados disponibilizados pela Prefeitura Municipal de Rondonópolis possui 115 indústrias instaladas em sua área.

Os distritos industriais Augusto Bortoli Razia abrigam 48 empresas, o parque industrial Fabrício Mendes abriga 35 empresas e o parque industrial Vetorasso 138 empresas.

As empresas que participaram desse trabalho estão localizadas nos Distritos Industriais Augusto Bortoli Razia e Parque Industrial Vetorasso, conforme informado anteriormente, já que os mesmos apresentam a maior concentração de empresas que produzem a uma escala nacional.

A pesquisa seguiu um formato teórico-empírico e descritiva, com abordagem qualitativa, e uma orientação de categorização na análise dos dados evidenciados por meio de coleta documental, registros, entrevistas e observação direta em campo das percepções dos gestores (Flores, 1994).

A ênfase do trabalho esteve na exploração das percepções dos gestores de empresas situadas nos distritos industriais de Rondonópolis, quanto às perspectivas em relação ao transporte ferroviário e a produção manufatureira na cidade.

As entrevistas foram realizadas com 3 coordenadores logísticos e 1 gerente nacional de transporte de empresas manufatureiras situadas nos distritos industriais da cidade e 1 gerente operacional de transporte da empresa responsável pelo transporte ferroviário na cidade de Rondonópolis. Prezou-se pelo sigilo dos nomes das empresas para a realização deste trabalho, a fim de zelar por informações importantes de cunho logístico. A escolha das empresas foi realizada levando em consideração o volume de produção, a importância no cenário industrial de Rondonópolis, e a localização.

Após delimitado a temática e as empresas a serem analisadas, buscou-se na literatura os pilares para a edificação do roteiro de pesquisa, e dos objetivos da pesquisa.

Foi elaborado e utilizado um roteiro de entrevistas que continha questionamentos sobre a logística de transportes utilizadas pelas empresas, tanto na aquisição de matéria-prima quanto na distribuição de produção, expectativa sobre o uso do modal ferroviário e a opção de instalação nos distritos industriais. Após a transcrição das entrevistas, foi estabelecida a análise por templates, conforme Flores (1994), que propõe uma sequência de passos para a análise geral de dados qualitativos, partindo da redução dos dados, que incluem separação dos elementos, identificação e classificação, e agrupamento.

Os dados foram categorizados em 10 categorias diferentes, são elas: escassez de opções de transporte, transporte próprio ou terceirizado, aquisição de suprimentos, canal de distribuição, reflexos da implantação da malha ferroviária, expectativa e sondagem, satisfação com o modal ferroviário, incentivo público para a utilização do transporte ferroviário, distrito industrial, e transporte ferroviário.

O enfoque da coleta de dados em campo visou identificar a percepção dos gestores das empresas manufatureiras em relação ao uso do transporte ferroviário na cidade de Rondonópolis, também buscou-se identificar se há incentivos dos órgãos públicos para o uso do mesmo, e se o nível de produção das empresas manufatureiras é compatível com esse modal, na visão delas.

\section{APRESENTAÇÃO E ANÁLISE DOS RESULTADOS}

A empresa E1 é brasileira, natural de Rondonópolis e atua no mercado de beneficiamento de grãos há 20 anos, possui 10 tipos de produtos e atende o mercado regional e algumas áreas dos estados vizinhos. A empresa E2 é norte-americana, atua na originação e 
processamento de grãos, fabricação de produtos alimentícios, bioenergia, produção de açúcar, e serviços portuários, está no mercado brasileiro há 45 anos e possui uma unidade de produção em Rondonópolis.

A empresa E3 é brasileira, atua com a produção de bebidas, está no mercado há 21 anos, possui produtos alcoólicos e não alcoólicos, e dentre 6 unidades fabris que possui uma está em Rondonópolis. A empresa E4 é norte-americana, atua na originação e processamento de grãos, produção de fertilizantes, produção de açúcar e etanol, biodiesel, processamento de cacau, processamento de palma, nutrição animal, e serviços logísticos e portuários, está no mercado brasileiro há 18 anos e possui uma unidade de produção em Rondonópolis.

A empresa E5 é brasileira, atua no segmento de transporte ferroviário, está no mercado há 18 anos, possui 12,9 mil quilômetros de linhas, 966 locomotivas e 28 mil vagões para transporte de mercadorias.

A primeira categoria analisada foi a percepção dos gestores quanto à escassez de opções de transportes, tendo apenas o transporte rodoviário como opção viária de obtenção de insumos e escoamento de produção, uma vez que o transporte ferroviário realizado no estado de Mato Grosso atende apenas o escoamento de grãos.

Como evidencia Gordinho (2003) que o Fundo Rodoviário Nacional em 1945 garantiu investimentos para a fomentação da malha rodoviária, mas a consolidação veio em 1952 e nos anos subsequentes quando em parceria com os Estados Unidos foi realizado um estudo para desenvolvimento econômico e a malha rodoviária foi eleita como a mais viável, apresentando menores custos de implantação e retorno mais rápido do investimento.

A ideia de fomentar o desenvolvimento socioeconômico nacional continuou se propagando e hoje o transporte brasileiro é refém do modal rodoviário.

Além disso, essa opção foi beneficiada pelo Programa de Petróleo Nacional e pela criação e produção de asfalto e combustível por parte da Petrobrás. O transporte rodoviário no Brasil, também, foi escolhido para a interiorização do país e ajudar a fomentar o crescimento nacional através das empresas automobilísticas.

O estado de Mato Grosso oferta o transporte rodoviário de maneira abundante suprindo toda a demanda do estado, mesmo que de forma precária, facilitando a escolha das empresas por esse modal.

A segunda categoria a ser analisada foi sobre a opção de transporte próprio ou terceirizado, os respondentes e sua maioria comentaram que a logística da empresa é própria, mas que os transportadores são terceirizados.

Dentre as quatro empresas, apenas uma utiliza transporte próprio. O entrevistado E1 utiliza as duas categorias de transporte, a fim de atender a demanda do estado de Mato Grosso e alguns estados vizinhos.

Houve uma convergência entre as empresas de amplitude nacional, que optaram pelo transporte terceirizado, mas com um setor de logística próprio. Nesse setor, as empresas visam à construção de roteiros de viagem que atendam sua demanda, além de suprir as necessidades dos contratados com: postos de combustíveis, para abastecimento, alimentação e descanso dos motoristas, e estradas mais seguras.

Além disso, as empresas manufatureiras definem o perfil das empresas de transporte contratadas e ficam responsáveis pela contratação da seguradora, o roteiro ainda inclui o tempo para a entrega da mercadoria ao destinatário, manifestações de notas e pagamentos de impostos. O transporte rodoviário possibilita uma flexibilidade de entrega que os outros tipos de transporte não possuem a entrega e coleta realizadas em qualquer lugar, mas a opção de terceirização ou não do mesmo fica por conta das análises das empresas. 
Sales (2000) afirma que, é necessário a roteirização do trajeto para especificar os pontos de demanda que serão atendidos e o tempo em que serão atendidos. Já Caixeta-Filho e Martins (20114) relatam que, a escolha do transporte envolve as características do mercado, tomadores de decisão, tipo de cargas, legislação, infraestrutura de transporte e tecnologia disponível.

Sendo assim, a opção de terceirização do transporte é realizada de maneira particular, pois além de envolver as decisões supracitadas ainda apresenta a opção custo de operação e manutenção de frota, e confiabilidade do serviço ofertado.

A terceira categoria questiona a aquisição de suprimentos por parte das empresas manufatureiras. Os entrevistados E2 e E4 por serem atendidos pela produção de matéria-prima realizada no estado indicam menos pontos desfavoráveis em relação às outras duas empresas, devido a distância para a fonte dos recursos.

Possuem fornecedores tanto na cidade de Rondonópolis, quanto em outras regiões do estado, o que aumenta a competitividade em relação aos custos com transporte.

Os entrevistados E1 e E3 indicam pontos desfavoráveis em relação à distância com seus produtores, onde a fonte de recurso de E1 abrange uma área de 800 quilômetros a 3.000 quilômetros. Isso ocorre, pois o seu produto é ofertado o ano todo, mas sua matéria-prima, arroz e feijão, são produzidos por safras e o estado não possui produtores o suficiente para a demanda, tendo que buscá-lo em outras regiões do país. O entrevistado E3 necessita de mais de uma fonte primária, sendo uma atendida pela região onde está instalada (qualidade da água para a produção de bebidas) e a outra não.

As distâncias percorridas pelas empresas são tratadas de formas diferentes, enquanto mil quilômetros são considerados curta distância para uma, para outra não. Mesmo assim, é importante ressaltar que todo esse deslocamento realizado para captação de matéria-prima é realizado pelo transporte rodoviário, inclusive aquele acima da distância média estipulada pela literatura, de 500 quilômetros (Rodrigues, 2014).

As empresas devem administrar sua cadeia de suprimento sob cinco aspectos diferentes: qualidade, evitar problemas com atraso e danos, visando à fidelidade do cliente; velocidade, tempo de espera do cliente, do pedido a entrega; tempestividade, atender o que foi determinado; flexibilidade, tanto a novos produtos, quanto a novos volumes demandados; e custos, para se ter vantagem através dos preços mais baixos ou margem de lucro alta conforme identificado em Harrison e Van Hoek (2003) citado por Almeida e Schlüter (2012).

Bowersox et al.(2006) citado por Almeida e Schlüter(2012, p.102)relata dois princípios que atuam sobre a eficiência dos transportes na logística, a economia de escala, que está relacionada à diminuição do custo por unidade de peso à medida que o volume de carga aumenta, e a economia de distância, relacionada à diminuição do custo de transporte por unidade de peso à medida que aumentam a distância percorrida.

Rodrigues (2014) ainda menciona dentre as vantagens do transporte ferroviário a capacidade de transporte de grandes lotes a longas distâncias e a provisão de estoque em trânsito.

Dos 5 aspectos citados por Harrison e Van Hoek (2003), o transporte tem ligação direta com quatro (Qualidade, Velocidade, Tempestividade e Custos), levando em consideração o nível de produção ofertado pelas empresas analisadas, pode-se utilizar os dois princípios de eficiência dos transportes na logística mencionados por Bowersox (2006) (economia de escala e de distância). E, especificamente, no caso do E3 pode-se utilizar o estoque em movimento, por necessidade da empresa. 
Sendo assim, tanto pelo volume de produção quanto pela distância a ser percorrida para a aquisição de matéria-prima, a utilização do modal ferroviário se torna operacionalmente viável.

A quarta categoria a ser analisada abordando questionamentos relacionados ao transporte para o canal de distribuição de seus produtos manufaturados.

Esses canais de distribuição, independente das distâncias abrangidas, são todos atendidos pela malha rodoviária. Apenas no caso do entrevistado E1, a malha ferroviária no momento não seria interessante para a distribuição de seu produto, pois, a empresa possui a maioria de seus clientes próximos e os atende com pouco volume e de maneira semanal, além de possuir poucos clientes localizados a mais de 500 quilômetros de distância. $\mathrm{O}$ foco de vendas está em âmbito regional, tanto que a empresa revelou atender clientes, em muitos casos, duas vezes na semana para que os mesmos evitem estoques.

Já os entrevistados E2, E3 e E4 atendem o mercado em âmbito regional e nacional, o que implica grandes distâncias e grandes volumes de produtos. Essas empresas relatam a deficiência da malha rodoviária na infraestrutura disponibilizada, pois a mesma pode afetar a qualidade do produto, possuem um tempo de entrega muito alto, principalmente pelo nível de tráfego e leis que regem o mercado, além dos riscos com sinistros e furtos.

Como já citado no item anterior por Harrison e Van Hoek (2003) apud Almeida e Schlüter (2012), o transporte pode influir: na qualidade, velocidade, tempestividade e custos dos produtos, devido ao tempo em que o mesmo permanece em movimento e mal acondicionado, na desfidelização dos clientes em casos de atrasos, por origens de causas naturais ou não, e nos preços dos produtos. Sendo assim, fere os aspectos de ampliação de vantagem competitiva das empresas (qualidade, velocidade, tempestividade e custos).

Rodrigues (2012) menciona as desvantagens do transporte rodoviário mencionadas pelos gestores das empresas em questão, a baixa qualidade da infraestrutura disponibilizada e o alto nível de tráfego das estradas, pontos que se relacionam com o moroso tempo de entrega.

Para essas empresas, o transporte ferroviário seria interessante, já que cobriria um alto volume de carga e grandes distâncias. Porém, é importante frisar que o transporte ferroviário necessita de um transbordo de carga realizado por caminhões, portanto exige uma integração modal para a realização do serviço.

Conforme Caixeta-filho e Martins (2014), a escolha do modal é realizada sob as seguintes perspectivas: capacidade, tempo de trânsito, serviços logísticos oferecidos adicionais ao transporte, perdas e danos, disponibilidade e qualidade das informações de transporte, custo de operação, confiabilidade, frequência do serviço, acessibilidade e flexibilidade de integração modal e segurança.

O modal ferroviário apresenta um custo alto para implantação, porém o seu custo operacional é baixo, é indicado para grandes distâncias, não sofre com o nível alto de tráfego, possui um baixo valor de frete e baixo consumo energético, sendo um transporte contínuo e confiável, conforme Rodrigues (2012).

O modal ferroviário, neste caso, reduziria o tempo de entrega dos produtos aqui produzidos, já que não é tão afetado com o tempo como o transporte rodoviário, e não possui um alto índice de roubos. Nesse contexto, a empresa deverá se preocupar apenas com o transbordo de cargas realizado por caminhões, já que o sistema ferroviário não disponibiliza a entrega porta a porta.

Sendo assim, ficará a cargo da empresa a logística de montagem de centros de distribuição para o serviço adicional realizado por caminhões, cobrindo as menores distâncias.

A quinta categoria aborda os reflexos da implantação da malha ferroviária para as empresas manufatureiras. 
O entrevistado E1 afirma que atualmente não identificou reflexos positivos ou negativos com a chegada da malha ferroviária na cidade, porém a empresa espera que futuramente com a sua expansão de vendas possa utilizar os serviços ofertados pela malha ferroviária, a fim de reduzir o lead time de entrega e os custos com o transporte.

Os entrevistados E2 e E4 relatam que os reflexos positivos estão relacionados apenas a exportação de grãos. O entrevistado E2 afirma que já realizou alguns testes com o modal, porém os resultados foram aquém do esperado. $\mathrm{O}$ transporte rodoviário, segundo a empresa, se mostrou mais rápido no processo de entrega, por isso necessita-se de mais investimentos em projetos para sanar as necessidades do mercado interno.

A empresa indica que nos pontos de coletas das ferrovias deve haver centros de distribuições comportando pequenos estoques que atendam as demandas regionais, já que o processo de retirada do pedido da fonte por locomoção via férrea até o destino é moroso.

O entrevistado E3 indica que até o momento não houveram reflexos negativos identificados, porém relata que não há espaço para produtos acabados no modal ferroviário da cidade de Rondonópolis, porém por ser uma empresa de bebidas foge do perfil da empresa de transporte ferroviário.

Como relata Rodrigues (2012), o transporte rodoviário pode realizar entrega sem o serviço multimodal. Por esse motivo e pelo fator histórico que envolve a malha rodoviária é mais simples, no momento, utilizar-se o mesmo, já que, o transporte ferroviário exige um nível alto de investimento para implantação e adequação as demandas das empresas.

A sexta categoria em análise abordou a expectativa de uso do modal ferroviário e sondagem das empresas, tanto as manufatureiras quanto a responsável pelo transporte ferroviário.

Todas as empresas afirmaram ter interesse na utilização dos serviços prestados pela malha ferroviária, porém apenas as empresas que atendem o mercado em âmbito nacional receberam ou realizaram sondagens para a realização do mesmo.

O entrevistado E1 relata que futuramente espera utilizar a malha ferroviária, afirmando que essa parceria será concretizada quando a empresa aumentar a sua gama de clientes, ou seja, alcançar expansão de mercado.

Os entrevistados E2, E3 e E4 possuem expectativa para a realização do serviço e, também, já receberam sondagens. Porém, as empresas identificaram um ponto negativo em comum em relação à malha ferroviária brasileira, a abrangência. Para essas empresas, a malha ferroviária brasileira deveria abranger maiores extensões, e leva-se um período considerável para a readequação da distribuição de produtos de maneira intermodal.

Para essas empresas, o trajeto realizado pela malha ferroviária não atende as necessidades das mesmas, isso pode ser ocasionado pelo uso da malha ferroviária apenas para projetos estratégicos, conforme Rodrigues (2014). Como no caso de Mato Grosso, o escoamento de grãos.

A expectativa da empresas ao uso do modal ferroviário se deve as vantagens que o transporte oferece. Conforme Almeida e Schlüter (2012) as ferrovias são seguras, apresentam baixo risco, em relação à avaria de produtos com acidentes, e não são gravemente prejudicadas pelo tempo ou tráfego competitivo.

Além disso, a malha ferroviária brasileira é composta por bitolas de diferentes tamanhos o que dificulta a integração interferroviária. Tendo que se utilizar a malha já existente e cobrir as grandes áreas não atendidas pelo modal com o transporte rodoviário. Herança do governo militar que consolidou a malha ferroviária em poucas empresas públicas, erradicou os ramais ineficientes e disseminou a ideia de transporte ferroviário apenas para projetos estratégicos (RODRIGUES, 2014). 
A sétima categoria em análise abordou a satisfação com o modal rodoviário. De maneira geral, as empresas se mostram insatisfeitas com o modal rodoviário, isso porque há muitas reclamações sobre diversos problemas que o afetam. Porém, ele é o único que os atende.

Como evidencia Schlüter (2012), o Brasil possui uma extensa malha rodoviária, que por conta das más administrações estaduais e federais encontra-se em péssimas condições de uso. Ribeiro e Ferreira (2000) afirmam que o modal é o mais expressivo no transporte de cargas do país, atendendo praticamente todos os pontos do território nacional.

Rodrigues (2012) relata que o modal rodoviário não é indicado a distâncias superiores a 500 quilômetros, que a capacidade de carga é menor que de outros modais, possui um alto nível de restrições de segurança, possui um intenso nível de tráfego, e que a malha rodoviária brasileira está desgastada.

Nos excertos, observa-se uma convergência das empresas quanto às insatisfações com a infraestrutura disponibilizada para a malha rodoviária, o que inclui as condições dos asfaltos, altos preços de pedágios nas estradas privatizadas e alto índices de acidentes.

Das quatro empresas analisadas, apenas o entrevistado E1 possui transporte próprio e ele foi o que apresentou o maior grau de insatisfação, não levantando nenhuma perspectiva positiva perante o transporte rodoviário. Já as empresas cujo transporte é terceirizado, mesmo não apresentando uma satisfação plena, os mesmos conseguiram identificar perspectivas positivas, ligadas a melhorias do serviço pela rigorosidade de seleção.

A oitava categoria em análise evidenciou o incentivo público para a utilização do transporte ferroviário.

Conforme relata Rodrigues (2012), a cultura que foi disseminada historicamente no Brasil nas sucessões de governos, associa o transporte ferroviário a projetos estratégicos e não como opção de transporte convencional, como o modal rodoviário. Além disso, as concessões ao uso da malha ferroviária são para empresas privadas, o que pode dificultar a participação de órgãos públicos no incentivo ao uso do modal.

Porém, mesmo o governo federal tendo acertado nas privatizações do modal ferroviário o modelo adotado engessa a entrada de novas empresas que queiram utilizar o modal para o transporte de carga.

As empresas manufatureiras analisadas declararam não ter recebido apoio de nenhum órgão público, municipal, estadual ou federal, para o uso do modal ferroviário, e todos os projetos iniciais realizados entre as empresas partiram do interesse privado, ou da empresa responsável pelo transporte ferroviário na cidade de Rondonópolis, ou das empresas manufatureiras instaladas no distrito da cidade.

A nona categoria analisada abordou a perspectivas dos gestores quanto à instalação das empresas nos distritos industriais de Rondonópolis-MT.

As empresas possuem seus motivos quanto à escolha do distrito industrial em que estão situadas, e com isso, foi possível encontrar duas convergências: uma em relação ao posicionamento geográfico da cidade de Rondonópolis, quanto à acessibilidade a outras regiões; e outra, em relação à infraestrutura disponibilizada pela prefeitura.

As empresas declaram que se sentem bem localizadas pela importância geográfica que a cidade de Rondonópolis possui, sendo corredor de escoamento de diversas regiões do país, além do estado de Mato Grosso ser um grande produtor de commodities. Sendo esse o discurso geral, as empresas também possuem suas opções peculiares, como nos casos dos entrevistados E2, E3 e E4.

Onde os entrevistados E2 e E4 levaram em consideração a demanda de transporte ofertadas em seus respectivos distritos e o entrevistado E3, produtora de bebidas, levou em consideração a qualidade da água existente em seu distrito industrial e a oferta de transporte. 
As empresas revelam que não possuem parceiras de produção nos locais, que todo o material secundário utilizado na produção vem de fora (rótulos, embalagens, etc.).

Fragomeni (2005) afirma que as empresas instaladas em um distrito industrial compartilham da mesma infraestrutura e são projetados para atender a demandas compatíveis de diferentes indústrias, mas o que as entrevistas explicitam é a falta de parceiros das empresas em análise.

O ponto negativo convergente entre as empresas é o da infraestrutura disponibilizada pela prefeitura municipal de Rondonópolis, as empresas reclamam a falta de saneamento, a má qualidade da rede de telefonia e internet, precariedade do asfalto e falta de asfalto, e precariedade da rede elétrica dos distritos industriais.

Como relata Buarque (1984), o que determina a localização dos distritos é a localização dos insumos, dos materiais de produção, disponibilidade da mão-de-obra, espaço físico disponível, clima, distância da fonte de combustível industrial, facilidade de transporte, distância e dimensão do mercado, disponibilidade de energia, água, luz e telefone, saneamento básico, segurança, incentivos e estrutura tributária.

Então, a opção de instalação das empresas em questão está relacionada ao posicionamento geográfico da cidade de Rondonópolis, próxima a outros grandes centros, e facilidade de alocação de transporte para escoamento de produtos manufaturados.

Nesse contexto, pode-se supor que o posicionamento geográfico estratégico da cidade de Rondonópolis é enviesado pela má administração dos distritos industriais. Já que o lado geográfico pode vir a funcionar como um chamariz para novos investimentos, gerando mais desenvolvimento socioeconômico, enquanto que a má administração por uma abordagem ampla, possa distorcer essa realidade.

A décima categoria analisada abordou apenas o gestor da empresa E5, responsável pelo transporte ferroviário da cidade de Rondonópolis. O entrevistado E5 se instalou no município de Rondonópolis, a fim de atender a demanda de escoamento de commodities aqui produzido, e também, ser um incentivo para a instalação de outras empresas no município que buscam a oferta do serviço de transporte ferroviário.

Confirmando o que relata Rodrigues (2014) ao se dirigir ao transporte ferroviário como ferramenta logística utilizada apenas em projetos estratégicos, como nesse caso o escoamento de grãos, e o que relata Almeida e Schütler (2012), que o modal é utilizado, principalmente, para produtos extrativos localizados distantes de portos e hidrovias.

O entrevistado E5 relata que devido a diversos tipos de grãos produzidos em diferentes épocas, o período entre safras é mínimo e o fluxo de cargas realizado pela empresa é muito grande. O que supri a necessidade de escoamento dos produtores e satisfaz as expectativas da própria empresa.

Grandes partes dos acordos realizados pela empresa ferroviária estão em contratos obrigando as empresas locais a manterem o uso total de sua capacidade.

Foi relatado que seus terminais são exclusivos para granéis sólidos (soja, milho, farelo) e para a produção de óleo de soja das empresas locais. Porém, mesmo a empresa revelando que comporta a produção de óleo de soja aqui produzido, até o momento só foram realizados testes iniciais.

O entrevistado E5 deixa claro que pretende atender todas as empresas que necessitam de transporte, independente do segmento atuante. Afirmação essa que pode ser levada em consideração as empresas manufatureiras que estão instaladas nos distritos industriais de Rondonópolis. 
Devido ao que descreve Rodrigues (2014) dizendo que o modal possui um alto custo fixo para implantação, pode-se deduzir que esse processo de atendimento de todas as empresas, de diferentes segmentos, que necessitam de transporte será gradativo, longo e moroso.

Assim como as empresas manufatureiras, a empresa E5 também relata não saber da existência de projetos ou incentivos de órgãos públicos em prol do uso do transporte ferroviário na região.

Devido ao que descreve Rodrigues (2014), dizendo que o modal possui um alto custo fixo para implantação, pode-se deduzir que esse processo de atendimento de todas as empresas, de diferentes segmentos, que necessitam de transporte será gradativo, longo e moroso. Porém, testes iniciais com algumas empresas já estão sendo realizado, fator que deve ser levado em consideração, já que o objetivo principal não são as empresas manufatureiras, mas sim os produtores de commodities, e o pouco tempo de operação. anteriormente.

O Quadro 1 apresenta todas as categorias de análise utilizados nesta pesquisa, relatadas

Quadro 1: Categorias para a análise.

\begin{tabular}{|l|l|}
\hline Escassez de Opções de Transporte & Expectativa e Sondagem \\
\hline Transporte Próprio ou Terceirizado & Satisfação com o Modal Rodoviário \\
\hline Aquisição de Suprimentos & $\begin{array}{l}\text { Incentivo Público para a Utilização do } \\
\text { Transporte Ferroviário }\end{array}$ \\
\hline Canal de Distribuição & Distrito Industrial \\
\hline $\begin{array}{l}\text { Reflexos da Implantação da Malha } \\
\text { Ferroviária }\end{array}$ & Transporte Ferroviário \\
\hline
\end{tabular}

Fonte: Elaborado pelo autor.

\section{CONCLUSÕES}

Fica explícito que as empresas optaram pelo modal rodoviário devido à escassez de diferentes modais disponíveis na região de Rondonópolis, problema originado pelo histórico do contexto de desenvolvimento socioeconômico nacional. Das quatro empresas analisadas, apenas a E1 necessita dos serviços do modal ferroviário, devido à distância e volume, para a aquisição de suprimentos, porém, em relação à distribuição de produtos as empresas E2, E3 e E4 mostraram a necessidade de utilizar o modal ferroviário.

Em relação à cadeia de suprimento (aquisição de matéria-prima e distribuição de produção), as empresas se mostram a favor do uso do modal ferroviária, principalmente para a distribuição de seus produtos. Porém dão ênfase na insuficiência de infraestrutura disponível para atendimento de suas necessidades.

O modal ferroviário atende poucas áreas de que as empresas necessitam e as integrações inter-regionais para a ampliação das linhas atendidas pelo modal ferroviário exige um investimento muito alto da iniciativa pública ou privada, devido o modal ferroviário ter o histórico de ser utilizado no Brasil para operações logísticas estratégicas e por não existir um padrão de tamanho regulamentado por órgãos públicos responsáveis.

Além disso, a ampliação das linhas ferroviárias brasileiras necessita de uma reorganização da malha rodoviária, no complemento da distribuição do escoamento desses 
produtos. Ou seja, exigem-se centros de distribuição, operações realizadas por caminhões, o que também exige investimentos por parte das empresas.

É preciso que o governo federal crie dois tipos de concessões, a primeira está relacionada à construção, ampliação e gestão da malha ferroviária, a segunda concessão está relacionada ao transporte, permitindo que mais de uma empresa utilizasse a malha ferroviária, aumentando a competitividade que inexiste no Brasil.

De maneira geral, as empresas não identificaram reflexos positivos ou negativos com a chegada da malha ferroviária na cidade de Rondonópolis, porém todas pretendem utilizar os serviços futuramente, tanto é que na maioria dos casos as sondagens a respeito do uso do modal ferroviário foram idealizadas pelas empresas manufatureiras.

As empresas se mostram insatisfeitas como o modal rodoviário, entretanto ele é o único que as atende, procurando ser utilizado da melhor forma. A insatisfação não advém das frotas disponíveis, mas, mais uma vez, da infraestrutura disponível e da forma como o mesmo é regulamentado.

Por parte das empresas não foi identificado nenhum incentivo ou projeto público para haver a utilização do transporte ferroviário, assim como, também, não foi identificado por parte da empresa de transporte. O que confirma a ideia do uso do transporte ferroviário para projetos estratégicos no Brasil, no caso de Mato Grosso temos o escoamento de grãos para a exportação.

O uso do modal ferroviário acarretará vantagem competitiva para as empresas analisadas, já que o transporte possui algumas vantagens se considerado em grande volume (economia de escala) ou em grandes distâncias (economia de distância). Traduz-se em qualidade, velocidade, tempestividade e menores custos.

Todas as empresas analisadas escolheram Rondonópolis para se situarem por conta do posicionamento geográfico estratégico que a cidade possui, sendo cortada pelas principais vias de escoamento do Centro-Oeste (BR163 e BR364). Porém todas as empresas analisadas não estão satisfeitas com a infraestrutura disponibilizada pela gestão pública local nos distritos industriais.

Sendo assim, existe um paradoxo em relação ao se possuir, de maneira natural, um posicionamento territorial estratégico, o mesmo está enviesado pelas más condições da infraestrutura disponibilizada aos que fomentariam o desenvolvimento socioeconômico regional.

A empresa responsável pelo transporte ferroviário tem o intuito de atender toda a demanda de transporte da região de Rondonópolis, inclusive das empresas manufatureiras, porém todos os projetos realizados para iniciar esse tipo de parceria foram realizados pelas empresas manufatureiras. Confirmando que o objetivo da malha ferroviária é o escoamento da produção de granéis.

Entende-se que as empresas manufatureiras esperam utilizar o transporte ferroviário, mas esse uso depende de uma reorganização da malha ferroviária, com a expansão para atendimento de novas áreas, e uma organização da própria malha rodoviária, para a distribuição dos produtos, de maneira porta a porta.

Assim, mesmo o processo de uso das empresas manufatureiras já ter começado, em fase de testes, deduz-se que o mesmo será gradativo, moroso e longo, uma vez que necessitará de maiores investimentos para as readequações.

Com isso, o transporte rodoviário mesmo não sendo indicado para a maioria dos casos analisados será, assim mesmo, utilizado, pois a logística brasileira já possui o desenho voltado para o modal, abrangendo maiores áreas de atendimento, de maneira precária, e provendo uma grande fonte de renda no quadro social do país. 


\section{REFERÊNCIAS}

ALMEIDA, C.; SCHLÜTER, M. Estratégia logística. 1 ed. Curitiba: IESDE, 2012.

AZEVEDO, B. Cluster. Os distritos industriais dos países em desenvolvimento. Red de Revistas Científicas de América Latina, el Caribe, España y Portugal, Toluca, v.1, n.2, p.99-121, 2003.

BALLOU, R. H. Logística empresarial. 1 ed. São Paulo: Atlas, 2012.

CAIXETA-FILHO, J. V.; MARTINS, R. Gestão logística do transporte de cargas. 1ed. São Paulo: Atlas, 2014.

FLORES, J. G.Análisis de datos cualitativos - aplicaciones a la investigación educativa. Barcelona: PPU,1994.

GORDINHO, M. C. Transporte no Brasil: a opção rodoviária. 1ed. São Paulo: Marca D’Água, 2003.

HOENICKE, N. O distrito industrial de Joinville/SC (1975-2007): análise crítica e propositiva. São Paulo, 2007. 137 f. Tese (Doutorado em Arquitetura e Urbanismo) Faculdade de Arquitetura e Urbanismo, Universidade de São Paulo.

LAURIA, I. Distritos empresariais como agentes de desenvolvimento regional em áreas públicas de Aparecida de Goiânia-GO. Goiânia, 2014. 98 f. Dissertação (Pós-Graduação em Desenvolvimento e Planejamento Territorial) - Desenvolvimento e Planejamento Territorial, Pontifícia Universidade Católica.

MACHADO, S. Dinâmica dos arranjos produtivos locais: um estudo de caso em Santa Gertrudes, a nova capital da cerâmica brasileira. São Paulo, 2003. 162 f. Tese (Doutorado em Engenharia de Produção) - Escola Politécnica da Universidade de São Paulo, Universidade de São Paulo.

NOVAES, A. G.; GONÇALVES, B. S.; COSTA, M. B.; SANTOS, S. Rodoviário, ferroviário ou marítimo de cabotagem? O uso da técnica de preferência declarada para avaliar a intermodalidade no Brasil. In: CONGRESO CHILENO DE INGENIERÍA DE TRANSPORTES, 13. 2007, Santiago. Florianópolis. 12 f.

PREFEITURA MUNICIPAL DE RONDONÓPOLIS. Rondonópolis, uma cidade pronta para investir. Disponível em: <http://www.rondonopolis.mt.gov.br/?pg=acidade\&intCatID=116>. Acesso em: 15 mar. 2015, 22:30:00.

RIBEIRO, P. C. C.; FERREIRA, K. A. Logística e transporte: uma discussão sobre os modais de transporte e o panorama brasileiro. In: XXII ENCONTRO DE ENGENHARIA DE PRODUÇÃO-ENEGEP,Anais...Curitiba: 2002. 
RODRIGUES, P. Introdução aos sistemas de transporte no Brasil e à logística internacional. 5 ed. São Paulo: Aduaneiras, 2014.

SALES, A. Logística integrada. Revista Eletrônica da União de Negócios e Administração, Belo Horizonte, v.5, n.3, p.61-82, 2000.

SILVA, H. Caracterização e Descrição do Terminal Multimodal de Alto Araguaia/MT: Influência no corredor Centro-Oeste.Piracicaba, 2010. 23 f. Pesquisa e Extensão - Logística Agroindustrial, Escola Superior de Agricultura "Luiz de Queiroz", Universidade de São Paulo.

SOUSA, C. Clusters industriais: vantagem competitiva e desenvolvimento regional. Porto Alegre, 2003. 97 f. Dissertação (Pós-Graduação em Economia) - Faculdade de Ciências Econômicas, Universidade Federal do Rio Grande do Sul. 